\title{
Comparison of the effects of flooding vs. low-oxygen gas on pea (Pisum sativum L. cv. 'Alaska') primary roots
}

\author{
Teruo Niki ${ }^{1}$, Mitsuo Takahashi ${ }^{2}$ and Daniel K. Gladish ${ }^{3}$ \\ ${ }^{1}$ Department of Cell Technology, Faculty of Engineering, Takushoku University, 815-1 Tate-machi, Hachioji, \\ Tokyo, 193-0985, Japan \\ ${ }^{2}$ Department of Chemical Science and Engineering, Tokyo National College of Technology, 1220-2 \\ Kunugida-machi, Hachioji, Tokyo, 193-8610, Japan \\ ${ }^{3}$ Department of Botany, Miami University, Hamilton OH 45011, USA \\ Corresponding author: D. K. Gladish, e-mail: gladisdk@muohio.edu, Phone+1-513-785-3257, Fax: \\ $+1-513-785-3145$
}

Received on May 27, 2010; Accepted on August 18, 2011

\begin{abstract}
Flooding reduces soil oxygen necessary for root growth. In some mesophytes low levels of oxygen are mitigated by the formation of aerenchyma or expansion of intercellular spaces. But root immersion in water may have effects on roots in addition to reducing oxygen levels. At temperatures $>15^{\circ} \mathrm{C}$ Pisum sativum primary roots develop cavities in the centers of their vascular cylinders in response to saturated or flooded conditions. In the present study we compared the response of flooded pea roots to their response to hypoxia without flooding by using an innovative system that allows separation of the gas environment of a root system from that of its shoot system. Seedlings were flooded after $4 \mathrm{~d}$ growth and compared to seedlings in unflooded medium and to seedlings in the gas-manipulation experiment. At $25^{\circ} \mathrm{C}$ in slightly moist vermiculite, roots $4 \mathrm{~d}$ after planting were exposed to a gas mixture with $10.5 \%$ oxygen and shoots to $20.5 \%$ oxygen and compared to normoxic controls. Oxygen levels in all containers were monitored, root growth was measured, and frequency and size of vascular cavities were determined for all treatments. Under flooding and low-oxygen gas, root growth was suppressed and vascular cavity frequency was strongly enhanced compared to controls. Significant differences in root growth responses were not seen between these differing hypoxic conditions, but low-oxygen gas caused larger cavities than flooding, which suggests flooding with water may have subtle effects different than simple hypoxia.
\end{abstract}

Keywords: aerenchyma, flooding, hypoxia, pea primary root, Pisum sativum L., vascular cavity

\section{Introduction}

The root system of a typical mesophytic plant normally relies mainly on the root-growing medium to convey the oxygen required for root growth and mineral absorption. This is because the tissues of such plants are often incapable of providing an internal path with rates of diffusion sufficient for the demand. The diffusion of oxygen is four orders of magnitude slower in water than in air (Ponnamperuma 1984, Kalita 1999, Drew et al. 2000). Furthermore, oxygen is less available in wet soil than in dry soil because water replaces air in some of the space among soil particles. Low oxygen availability (hypoxia) due to flooding can significantly reduce root growth and productivity of many plants.

On the other hand, some mesophytes have evolved variations in development and anatomy that do provide a path of enhanced diffusion through their organs, such as extensive intercellular spaces and aerenchyma (Armstrong 1970, Drew 1977, Drew et al. 1985, Justin and Armstrong 1987, Drew et al. 2000, Evans 2003). The ability of a plant to facultatively produce aerenchyma in response to flooding has been most thoroughly demonstrated and analyzed in Zea mays, and the longitudinal channels thus produced convey enough oxygen through the roots to enable them to maintain basic functions and even to continue growing (Drew 1977; Drew et al. 1979; Drew et al. 1985; Atwell et al. 1988; Gunawardena et al. 2001).

Lu et al. (1991) and Niki et al. (1995) reported that long, continuous cavities frequently develop in the centers of vascular cylinders of pea (Pisum sativum) primary roots grown in warm $\left(>15^{\circ} \mathrm{C}\right)$, moist condi-

Niki T, Takahashi M, Gladish DK 2011 Comparison of the effects of flooding vs. low-oxygen gas on pea (Pisum sativum L. cv. 'Alaska') primary roots. Plant Root 5:31-39. doi:10.3117/plantroot.5.31

Copyrights 2011, Plant Root (JSRR), www.plantroot.org 
tions. It was shortly confirmed that many other species of legumes form vascular cavities (VC) similarly (Rost et al. 1991). In continuous warm conditions, VC in pea primary roots are relatively narrow (Niki and Gladish 2001), and the frequency of VC occurrence in seedling populations varies 20 to $100 \%$, depending positively on the degree of saturation of the growth medium (Gladish and Niki 2000). There is some circumstantial evidence that large VC induced by sudden flooding in primary roots of pea (Pisum sativum) may serve as a kind of inducible aerenchyma (Niki and Gladish 2001, Gladish et al. 2006, Gladish and Niki 2008).

Natural soils usually have very complex and sometimes heterogenous composition and structure (Ponnamperuma 1984; Kalita 1999). In vivo in the field when plant root systems become flooded they experience more than a simple reduction in oxygen availability. The choice of using solution culture to study the effects of hypoxia-induced aerenchyma is certainly understandable, given that waterlogging is the most common cause of hypoxia in a rhizosphere. The method allows investigators to minimize variables. It is not known, however, to what degree physiological and morphological changes caused by flooding are affected by the increase in water in the soil (or other medium) rather than the decrease in oxygen availability.

It is our opinion that the current understanding of these changes under hypoxia mentioned above has been limited by the inability to separate the effects of oxygen deprivation per se from possible effects associated with changes in the water amount and other factors that this causes in the rhizosphere, such as $\mathrm{pH}$ changes (Ponnamperuma 1984) or endogenous ethylene entrapment as a result of immersion (Drew et al. 1979). In this paper we present a technique that is promising for making changes in oxygen availability or for measuring changes of oxygen concentration in the rhizosphere without changing the water potential of the medium. This system can separate the aerial and subterranean environments around individual plants. We expected this method to permit the evaluation of the effects of low oxygen availability on primary root growth and vascular cavity formation in pea. We believed that we could create an oxygen environment for root and shoot systems more like that experienced in nature during flooding and mimic the hypoxia induced by flooding without actual immersion in water.

\section{Materials and Methods}

\section{Cultivation of plants for flooding treatment}

Cultivation methods were modified after Gladish and
Niki (2000). For flooding treatments, tall, heat- and pressure-resistant polypropylene $1 \mathrm{~L}$ beakers $(8.8 \mathrm{~cm}$ diameter at top, $21 \mathrm{~cm}$ height) were filled with coarse (2.5-7 $\mathrm{mm}$ particle diameter) vermiculite (GL grade, Nittai Corp., Ibaraki, Japan). The vermiculite was then moistened with $375 \mathrm{ml}$ of distilled water (DW). The beaker tops were covered with aluminum foil and sterilized by autoclave at $120^{\circ} \mathrm{C}$ for $70 \mathrm{~min}$. After autoclaving no free-standing water remained in the beakers. Vermiculite treated in this way poured freely from the beaker as though dry, so it will hereafter be referred to as "slightly moist vermiculite" to contrast it with flooded vermiculite. Under sterile conditions vermiculite was removed down to $7 \mathrm{~cm}$ from the top of the beaker to allow a small headspace and medium to cover the seeds. Pea seeds (Pisum sativum L. cv. Alaska) that had been surface-sterilized for $5 \mathrm{~min}$ in a solution of $1 \%$ sodium hypochlorite plus six drops of Tween 20 surfactant $\mathrm{L}^{-1}$ were placed on the vermiculite surface $(\mathrm{n}=22-25$ per beaker). The seeds were then covered with $2 \mathrm{~cm}$ of the removed vermiculite, and the beakers were re-covered loosely with the original sterile foil and placed in a growth chamber at constant $25^{\circ} \mathrm{C}$ in continuous darkness. Four and $5 \mathrm{~d}$ after planting seven beakers each were sampled to determine primary root length and presence of vascular cavities to serve as pre- and post flooding controls ( $4 \mathrm{~d}$ and $5 \mathrm{~d}$ controls, respectively). After $4 \mathrm{~d}$ seven other beakers were flooded with DW to just below the planting level and sampled $1 \mathrm{~d}$ later to serve as the flooding treatment $(4 \mathrm{~d}+1 \mathrm{~d}$ flooding treatment).

Growth tubes for controlled gas environment experiments

Cultivation methods for seedlings in growth tubes were as described above for flooding treatments, except that the modified beakers (growth tubes) were used (Fig. 1). Before planting seeds, a petroleum jelly/paraffin impregnated tissue partition disk or an unmodified acryl ring (control) was placed on the vermiculite surface after vermiculite was removed down to $7 \mathrm{~cm}$ from the top of the beaker. Petroleum jelly/paraffin-impregnated tissue paper was used for a partition to divide the upper and lower parts of a growth tube (Fig. 1-2). Petroleum jelly and paraffin (both Wako Pure Chemical, Osaka, Japan) in a 5:1 ratio were melted at $52-54^{\circ} \mathrm{C}$ and mixed well. Kimwipe tissues (Kimberly-Clark, Roswell GA, USA) trimmed into appropriately-sized discs were immersed in the melted petroleum jelly/paraffin solution, and then allowed to cool on a flat screen. These impregnated tissue paper disks were attached onto an acryl ring with sealing tape (Fig. 2). The sealing tape also served to produce a tight fit when the 


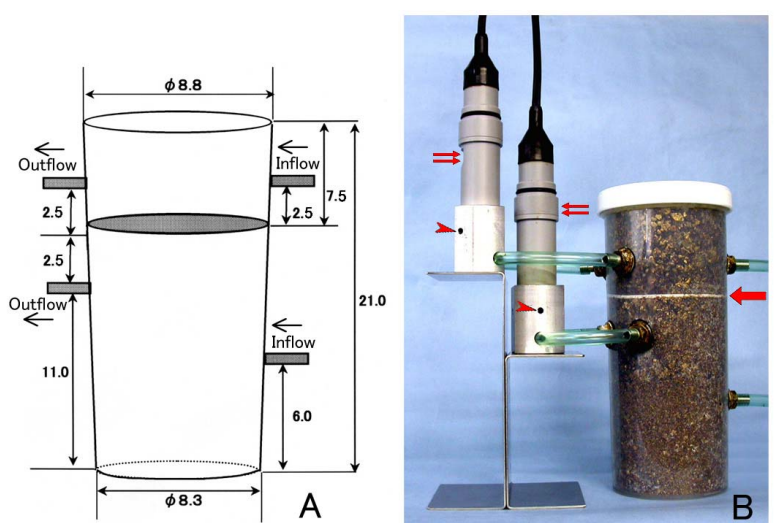

Fig. 1 Controlled gas-environment plant tube for germination and growth of seedlings per Fig. 3. (A) Schematic drawing of the growth tube. Arrows show the direction of flow air. The inflow and outflow orifices were stainless steel. Dimensions are $\mathrm{cm}$. (B) The growth tube was closed with a screw-cap during gas treatments. Dissolved oxygen sensor (DO; double arrows) were positioned to optimize gas flow. Single arrow indicates partition for separating the upper compartment from the lower compartment. Arrowheads indicate gas exit openings ("leak valves").

partition disk was placed into the growth tube Surface-sterilized pea seeds (cv. Alaska; $n=22-25$ per beaker) were laid on the partition disk, or directly on the vermiculite surface (control, acryl ring with no partition) and covered with $2 \mathrm{~cm}$ of the removed vermiculite as above. The foil cover was then loosely replaced on the growth tube, all the gas orifices were uncovered to allow gas exchange. The growth tube was then placed in a growth chamber in continuous darkness at $25^{\circ} \mathrm{C}$. The loose-fitting foil cover and uncovered orifices allowed air exchange but maintained sterile conditions for the first $3 \mathrm{~d}$, during which time seeds imbibed water and germinated.

\section{Apparatus for delivery and monitoring of air and low-oxygen gas mixes}

Three $\mathrm{d}$ after sowing, the foil was then replaced with a plastic screw cap, and the growth tube was connected to the gas supply and DO sensor system while inside a growth chamber. Compressed normoxic air or a low-oxygen gas mixture was bubbled through water in "flow indicators" and delivered to growth tubes at regulated flow rates $\left(100 \mathrm{ml} \mathrm{min}^{-1}\right)$ at $101 \mathrm{kPa}($ Fig. 3). Low oxygen gas mixtures were generated by mixing air and nitrogen gas supplied by compressed gas tanks (Fig.3). Oxygen concentration was detected and monitored by using Clark-type dissolved oxygen (DO) sensors (Horiba model OM-14, Kyoto, Japan) and the sensors were calibrated with flowing normoxic air $\left(100 \mathrm{ml} \mathrm{min}^{-1}\right.$ ) just before experiments began. The analog signals from the DO sensors were converted to a digital signal by using a digital multimeter (Keithley

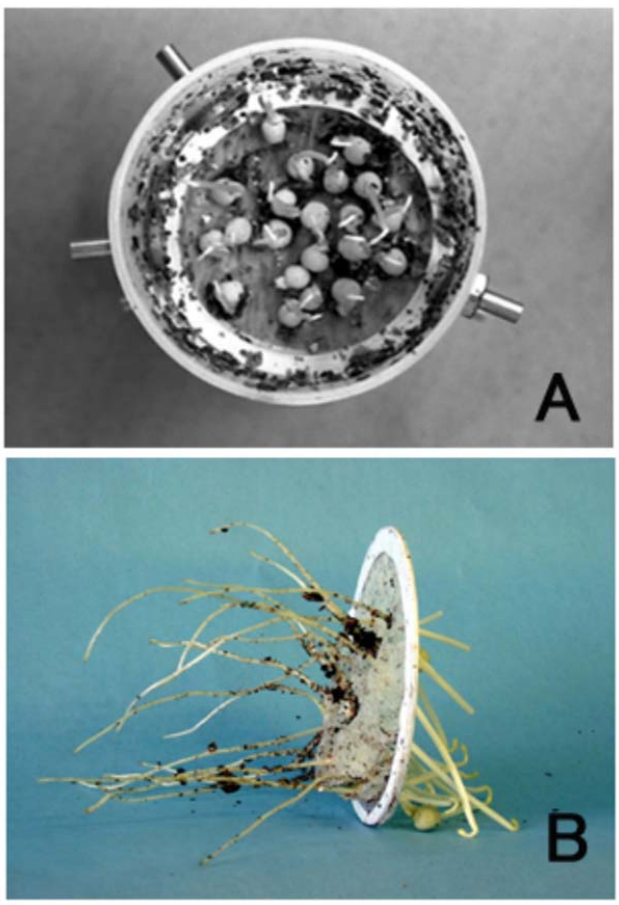

Fig. 2 Germination and growth of pea (Pisum sativum) in a growth tube. To test the "growth tube" system, seeds were planted in slightly moist vermiculite on a partition made from petroleum jelly/paraffin-impregnated tissue and an acryl ring or in a growth tube with only an acryl ring as control. These were germinated and grown in the growth tube at $25^{\circ} \mathrm{C}$ in continuous darkness for $3 \mathrm{~d}$ covered by loose-fitting foil, then sealed and infused with normoxic air for $1 \mathrm{~d}$. (A) View from above after removing the vermiculite medium from above the partition. (B) Roots were able to readily penetrate a partition.

Instruments model DMM 2000-SCAN, Cleveland OH, USA) monitored automatically by a personal computer. Sensor units were constructed for precisely measuring temperature and fine changes of oxygen concentration in gases in the system (Fig. 1B). The DO sensors were inserted into custom-manufactured aluminum cylinders (fabricated at Takushoku University College of Engineering, Hachioji, Japan) with joining holes to accept vinyl tubing from the growth tube or reference gas sources. These cylinders were fitted with flow-limiting "release" holes to allow regulated exit of gases while maintaining a small back-pressure in the system. The outflow gas from the orifices of the upper and lower parts of the growth tube was connected to sensor units via vinyl tubing. Normoxic air from a compressed-air tank was supplied to the upper and lower inflow orifices (Fig. 1) for the next $1 \mathrm{~d}$. To ensure system stability, gases were run through the gas delivery system bypassing the growth tube for the first $0.5 \mathrm{~h}$ of a trial before gases were introduced to a growth tube. Percent oxygen was quantified as described above at least five times for each partition possibility trial (no petroleum jelly/paraffin impregnated tissue disc partition, no 


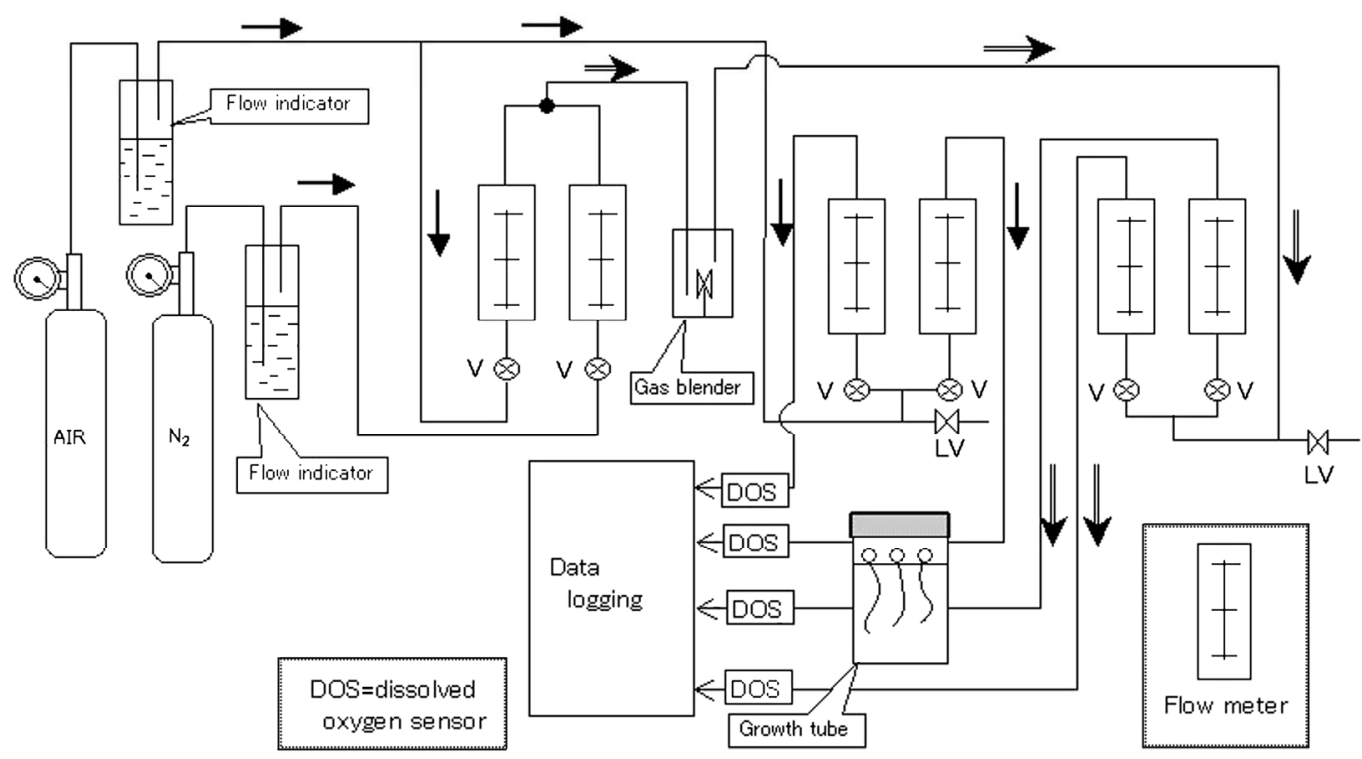

Fig. 3 System for manipulating oxygen concentration in a controlled gas-environment plant growth tube (cylindrical chamber). The roots were exposed to a regulated low-oxygen level while the shoot systems were exposed to ambient oxygen level. The oxygen level in the outflow from the growth tube's compartments were compared simultaneously to each other and to inflow oxygen levels. Bold arrows adjacent to lines indicating tubing show direction of gas flow. AIR: compressed normoxic air. $\mathrm{N}_{2}$ : compressed nitrogen gas. V: control valve for flow rate. LV: "leak valve" for pressure relief. DOS: dissolved oxygen sensor. Thin arrows from DOS to the data logger represent electrical connections. The system also included bubbler-type flow indicators, flow meters, a gas blender to insure uniform mixing of air and nitrogen gas, a growth tube (modified 1 L polypropylene plastic beaker), and a data logger controlled by a desktop personal computer.

developing seedlings; tissue partition present, no seedlings; tissue partition present, seedlings present). A trial was conducted with 12 seeds rather than 25 to test the effect of root penetration of the barrier on its separation abilities

After $3 \mathrm{~d}$ in the growth chamber and $1 \mathrm{~d}$ of normoxic air exposure (top and bottom), some growth tubes ( $\mathrm{n}=7$ tubes) were sampled for root length measurement and the presence of vascular cavities (4 $\mathrm{d}$ controls). For other growth tubes ( $\mathrm{n}=7$ tubes) the lower, root-bearing zones were then exposed to a low oxygen air/nitrogen mixture $(10 \%$ oxygen, $10.1 \mathrm{kPa}$ partial pressure) while the upper inflow orifices continued to receive normoxic air for $1 \mathrm{~d}(3 \mathrm{~d}+1 \mathrm{~d}$ air $+1 \mathrm{~d}$ gas treatment). Some growth tubes ( $\mathrm{n}=7$ tubes $)$ were continuously provided normoxic air via the upper and lower inflow orifices for $1 \mathrm{~d}$ ( $5 \mathrm{~d}$ controls). At the end of the gas flow treatment the primary roots were sampled for root length measurement and the presence of $\mathrm{VC}$.

\section{Evaluation of root growth and cavity formation after flooding or low oxygen gas}

After treatments, primary root lengths were measured and freehand sections were taken variously 1, 2, 3 and/or $5 \mathrm{~cm}$ from the root tip of primary roots from each seedling to determine if vascular cavities were present. A beaker or growth tube was also prepared for each treatment category for the purpose of measuring VC cross-sectional area by image analysis using Photoshop Extended CS5-JPL (Adobe Systems, Singapore). 15-16 roots were randomly selected from each beaker and free-hand sectioned at the same locations as above. These sections were stained with $0.025 \%$ toluidine blue $\mathrm{O}$. The first ten from each growth tube or beaker with a VC were digitally photographed and analyzed. If there were less than ten but more than two with $\mathrm{VC}$ in the sample group, they were all analyzed.

\section{Results}

Oxygen levels in beakers of slightly moist vermiculite loosely covered with aluminum foil were $8.4-8.9 \mathrm{mg}$ $\mathrm{L}^{-1}(20.9 \% \mathrm{~V} / \mathrm{V})$ in gas phase with or without young seedlings. When such beakers were flooded with water, the oxygen levels very rapidly dropped to about $3.5 \mathrm{mg} \mathrm{L}^{-1}$ in liquid phase. In flooded beakers with developing root systems the oxygen levels subsequently slowly decreased to about $2.0 \mathrm{mg} \mathrm{L}^{-1}$ within 18 h (Fig.4).

The gas delivery apparatus (Fig. 3) successfully maintained constant flows of gases through the upper and lower parts of the growth tubes at the desired oxygen levels for the duration of all trials except when a partition was not present in the growth tube. Low-oxygen level in the lower (root-zone) compart- 


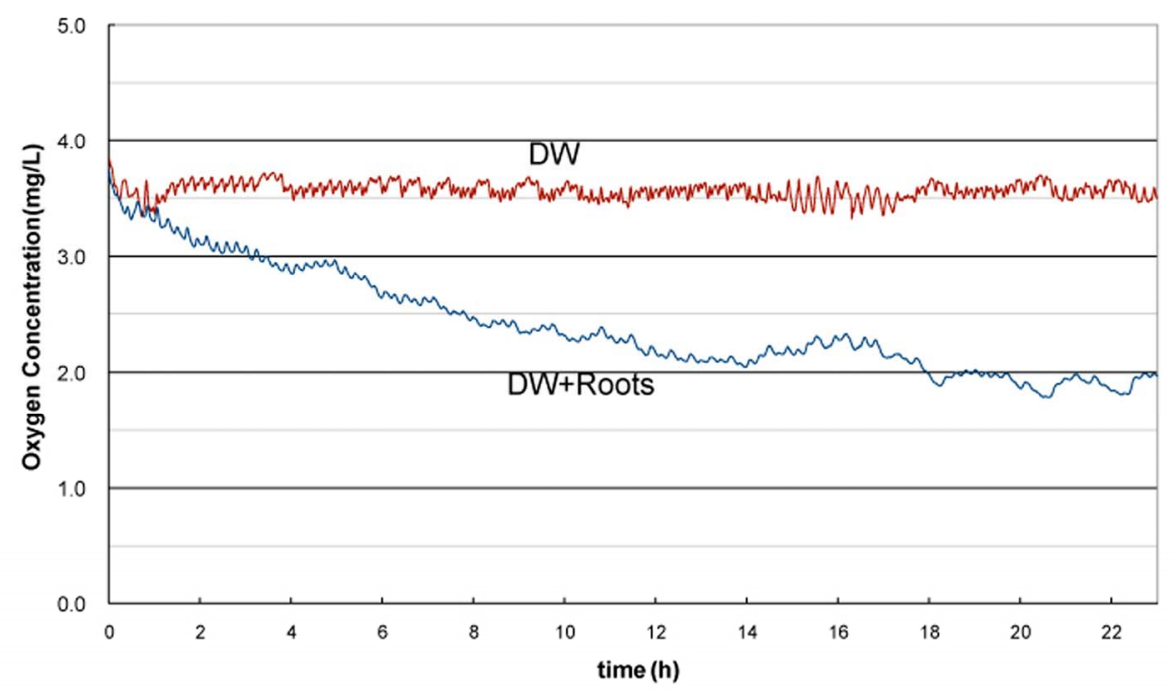

Fig. 4 Oxygen concentration measured over time using a dissolved oxygen sensor in $1 \mathrm{~L}$ beakers of flooded vermiculite with and without pea primary roots present. DW: distilled water. ment of the growth tube was readily and dependably controlled by initially adjusting the flow ratio of air and nitrogen gas (Fig. 5). With no partition tissue (acryl ring only), air introduced into the upper part of the growth tube and a low-oxygen gas mixture introduced into the lower part of a growth tube predictably became mixed (Fig. 5A). When the upper and lower parts were partitioned by petroleum jelly/paraffin-impregnated tissue paper partitions, oxygen concentrations of outflow gases from the upper and lower parts typically were shifted by less than $0.5 \%$ (Fig. 5B). When roots perforated a partition (Fig. 2), outflow gases from the upper and lower parts were not shifted by more than $1.5 \%$ oxygen, the lower compartment being more strongly affected than the upper (Fig. 5C). On the other hand, this shows that, while separation was otherwise good, perforation of the tissue barrier by roots did slightly increase transfer of oxygen from the upper to the lower part of a growth tube. Reducing the number of seeds by half did not significantly alter this result (data not shown). Long-term monitoring ( $24 \mathrm{~h})$ showed that the system maintained levels into and out of growth tubes and maintained separation reliably (data not shown).

Root growth (length) for controls at $4 \mathrm{~d}$ was slightly less in growth tubes with partitions compared to unmodified beakers and at $5 \mathrm{~d}$ it was slightly more, but the differences were not significant ( $t$-test, $p \leq 0.1$; Fig. 6). Differences in mean growth after $5 \mathrm{~d}$ between flooding-treated and low oxygen gas-treated primary roots were not statistically significant ( $t$-test, $p \leq 0.1$; Fig. 6). Exposing roots to flooding in beakers or to half of ambient oxygen level in a growth tube with a partition resulted in significant reductions in growth rates compared to controls for each treatment group ( $t$-test, $p \leq 0.01$; Fig. 6).

Roots exposed to normal air in a growth tube grew the same amount in $5 \mathrm{~d}$ as roots in unmodified,

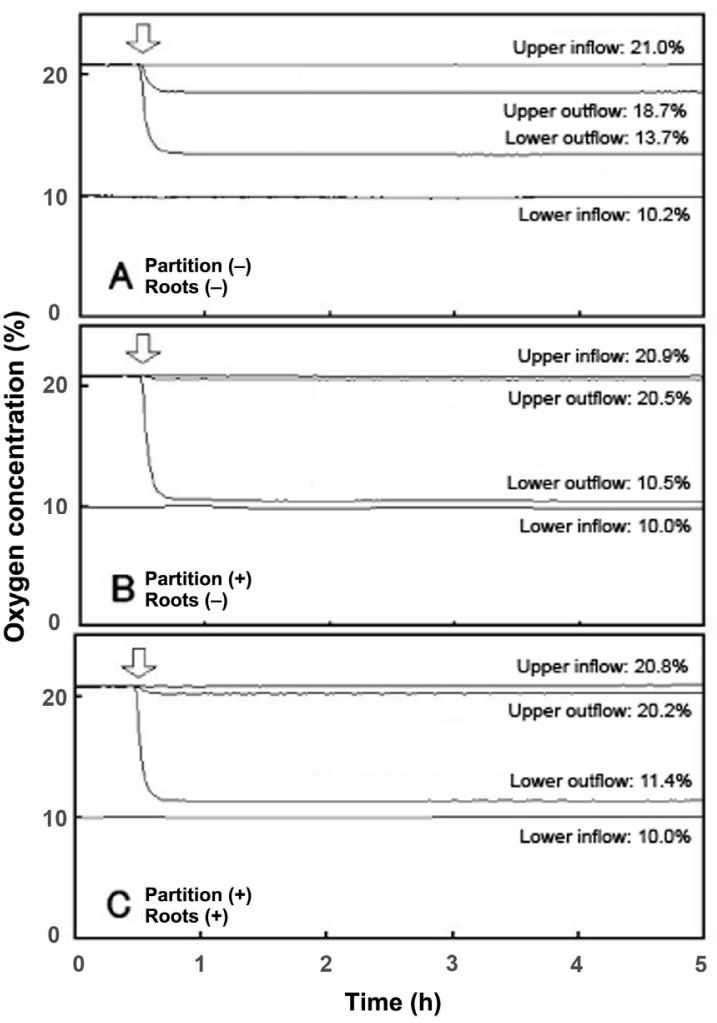

Fig. 5 Typical oxygen levels of inflow and outflow gases of growth tubes. (A) Oxygen levels of a growth tube without a partition. (B) Oxygen levels when a petroleum jelly/paraffin-impregnated tissue barrier was present. (C) Oxygen levels when petroleum jelly/paraffin impregnated tissue paper and plants were present. Arrow shows the start point when gas was admitted into the growth tube. Partition $(+)$, petroleum jelly/paraffin impregnated tissue paper partition was present. Partition (-), no partition, only acryl ring present in the growth tube. Roots $(+)$ and (-), presence and absence of pea seedlings. Separation between the upper and lower part of the growth tube was only slightly affected by perforation of the barrier by pea primary roots. 
unflooded beakers, but roots in normal air in a growth tube had significantly more frequent $\mathrm{VC}$ formation (Fig. 7). These $\mathrm{VC}$ also tended to be away from the tip. Primary roots grown in a beaker under control conditions either had no $\mathrm{VC}$ or a narrow one $3 \mathrm{~cm}$ or more from the tip (Fig. 7; Table 1). Primary roots grown in a growth tube with a partition with normoxic air-flow during the fifth day either had no $\mathrm{VC}$ or a moderately wide one.

VC typically were most common $1-2 \mathrm{~cm}$ from root tips under flooding or low oxygen air (Fig. 7). The frequency of $\mathrm{VC} 1 \mathrm{~cm}$ from the tip was very much higher than $4 \mathrm{~d}$ or $5 \mathrm{~d}$ controls regardless of the cause of hypoxia ( $t$-test $p \leq 0.01$; Fig.7) Flooding and 10\% oxygen gas mixture were highly, and equally, effective at inducing vascular cavities near the tip (1 $\mathrm{cm}$ from tip), but low-oxygen air was significantly more effective at triggering $\mathrm{VC}$ formation in older primary vascular tissues of the roots $(2-3 \mathrm{~cm}$ from the tip) than flooding ( $t$-test, $p \leq 0.05$, Fig. 7). Hypoxic conditions, such as during flooding or exposure to low-oxygen gas, induced greater frequency of cavity formation and usually larger cavities in comparison to those few that formed in the controls (Fig.7, Table 1).

\section{Discussion}

The results show that the apparatus used in this study for creating a hypoxic rhizosphere in the absence of waterlogging was stable and reliable (Fig. 5), and in several ways produced comparable results with respect to growth and the formation of vascular cavities (VC) as flooding (Figs. 6-7). The study by

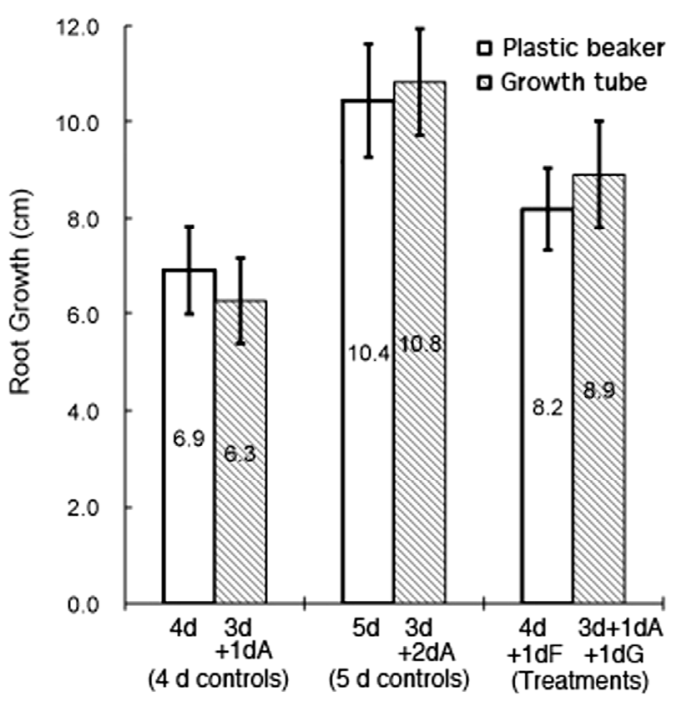

Fig. 6 Effect of flooding versus exposure to low-oxygen gas on growth of pea primary roots. All treatments were initiated and held in the dark at $25^{\circ} \mathrm{C}$ in a growth chamber for various times (below). The upper part of growth tubes (shoot system) always were exposed to normoxic air. $4 \mathrm{~d}$ and 5d: seedlings grown in slightly moist vermiculite (375 $\mathrm{ml}$ water $\mathrm{L}^{-1}$ vermiculite) in $1 \mathrm{~L}$ plastic beakers loosely covered with foil for $4 \mathrm{~d}$ and $5 \mathrm{~d}$, respectively. $4 \mathrm{~d}+1 \mathrm{dF}$ : roots grown for $4 \mathrm{~d}$ in slightly moist vermiculite, then flooded for one day. $3 \mathrm{~d}+1 \mathrm{dA}$ and $3 \mathrm{~d}+2 \mathrm{dA}$ : seedlings grown in slightly moist vermiculite in a growth tube with a root/shoot partition and loosely covered with foil for $3 \mathrm{~d}$, then sealed and exposed to flowing normoxic for 1 or $2 \mathrm{~d}$, respectively. $3 \mathrm{~d}+1 \mathrm{dA}+1 \mathrm{dG}$ : seedlings treated as $3 \mathrm{~d}+1 \mathrm{dA}$, then the roots were exposed to a low-oxygen gas mixture $\left(10 \% \mathrm{O}_{2}\right)$ for $1 \mathrm{~d}$. Error bar $=1 \mathrm{SD}$ interval $(\mathrm{n}=22-25$ seeds per beaker or growth tube, seven beakers or growth tubes for all trials).

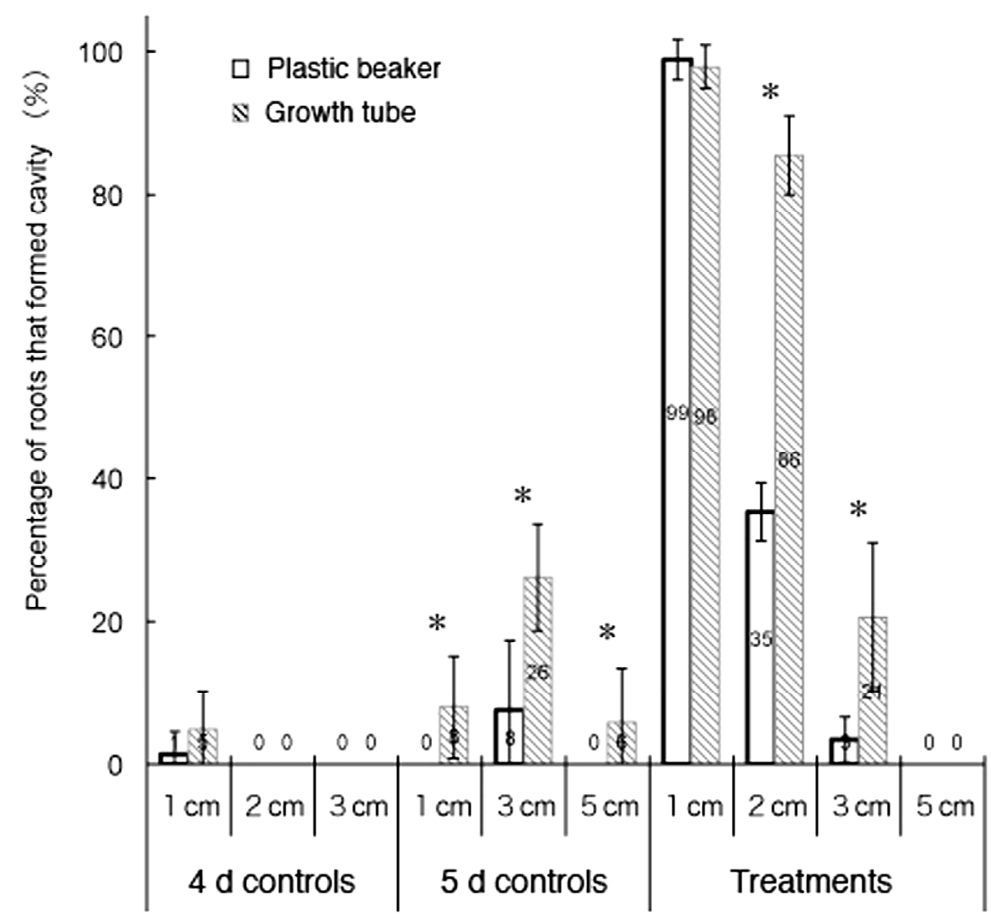

Fig.7 Distribution and frequency of vascular cavities after flooding or exposure to low-oxygen gas versus controls in pea primary roots (same seedlings and treatments as described in Fig. 6). Error bar $=1$ SD interval (n $=22-25$ seeds per beaker or growth tube, seven beakers or growth tubes for all trials). *Data were significantly different $(t$-test, $p \leq 0.05)$ when compared to the same root region (beakers vs. growth tube trials). 
Gladish and Niki (2000), which also used pea (Pisum sativum) primary roots and involved manipulation of the rhizosphere oxygen levels, had as a shortcoming that the shoot systems were exposed to the same atmosphere as the root systems. Since developing cotyledons and epicotyls in darkness are doubtless stressed by hypoxia too, and because it is not known how their response to hypoxia may affect a developing root system, new methods were required to address this problem. Furthermore, the results showed that a partition between the upper and lower parts of a growth tube (for the shoot system and root system respectively) was necessary if management of desired differences in oxygen levels were to be accomplished (Fig. 5A-B). The results also showed that penetration of the barrier by roots allowed only a small increase in the mixing of gases between the two compartments (Fig. 5C)

Gladish and Niki (2000) reported that pea roots in well-aerated, circulating water always make cavities unless the temperature is $\operatorname{cool}\left(10^{\circ} \mathrm{C}\right)$, and pea roots in warmer $\left(25^{\circ} \mathrm{C}\right)$ but slightly moist vermiculite make cavities much less frequently (ca. $25 \%$ of the population. The difference in absolute water potential between our "slightly moist" vermiculite, which suppresses the frequency of $\mathrm{VC}$ formation, and vermiculite saturated to "field capacity", which favors frequent VC formation (Lu et al., 1991; Gladish and Niki 2000) is slight (Tadashi Hirasawa, pers. comm.). Nevertheless, the water amount in the medium, independent of oxygen level, does seem to have a positive influence on VC formation (Gladish and Niki 2000). Consistent with this observation, Ober and Sharp (1996) found by direct measurement using an oxygen microelectrode that intracellular oxygen was less in the centers of maize roots growing in an aerated solution culture than roots growing in wet vermiculite. Since, from the outer limit of the water boundary layer on the epidermis inward, the roots in their experiment were the same (i.e., all cells were immersed in an aqueous continuum, as is typical in a plant tissue), this suggests that what matters for root internal oxygen status in the absence of pre-existing aerenchyma is the nature of the oxygen-bearing medium beyond the boundary layer on the root. Such evidence causes us to argue that factors enhancing the formation of $\mathrm{VC}$ in roots are more complex than relative oxygen availability alone can explain.

In the present study, root growth repression due to exposure to low-oxygen gas (approx. 10-11\% oxygen) was similar to that caused by flooding. Over time, though, the respiratory demand of the roots further reduced oxygen availability under flooding (Fig. 4). Given that measured oxygen levels in flooded beakers were eventually less than one-fourth the levels in unflooded ones, but inhibition of growth was not so different than exposing them to low-oxygen air, this shows that VC may serve as aerenchyma that compensates during flooding. On the other hand, because the oxygen availability declined with time under flooding but did not under low-oxygen gas, one would predict that the frequency of VC formation would be greater under flooding than in low-oxygen gas. But this was not the case (Fig. 7). This result suggests that water-induced hypoxia has a somewhat different influence (or magnitude) than low-oxygen gas in $\mathrm{VC}$ formation. It is noteworthy that there was a difference in cavity frequency between the $5 \mathrm{~d}$ beaker controls and the $5 \mathrm{~d}$ growth tube controls. We think this was probably not because of a relative humidity difference in the rhizosphere air spaces because gases were always bubbled through water before being delivered to the growth tube, but a physiological effect from the flowing of the gases through the rhizosphere, by comparison to still air in the standard beakers, cannot be ruled out.

When pea seeds were germinated and grown in control conditions, cavity formation did occasionally occur as reported previously (Gladish and Niki, 2000; Niki and Gladish, 2001). But these cavities were

Table 1 Cross-sectional areas $\left(\mu \mathrm{m}^{2}\right)$ of pea root vascular cavities due to exposure of roots to flooding with water, exposure to low-oxygen concentration gas, and controls.

\begin{tabular}{ccccc}
\hline Distance from root tip & $5 \mathrm{~d}$ unflooded control & $4 \mathrm{~d}+1 \mathrm{~d}$ flooded & $4 \mathrm{~d}+1 \mathrm{~d}$ air control & $4 \mathrm{~d}+1 \mathrm{~d} 10 \% \mathrm{O}_{2}$ gas \\
\hline $1 \mathrm{~cm}$ & no cavities & $6981 \pm 3372 \mathrm{a}$ & $(2$ or fewer $)$ & $11,523 \pm 2789 \mathrm{a}$ \\
$2 \mathrm{~cm}$ & no cavities & $7506 \pm 3742 \mathrm{~b}$ & no cavities & $10,652 \pm 4276 \mathrm{~b}$ \\
$3 \mathrm{~cm}$ & $(2$ or fewer $)$ & $7618 \pm 4740 \mathrm{c}$ & $5765 \pm 2311 \quad(3)$ & $4972 \pm 3332 \mathrm{c}$ \\
$5 \mathrm{~cm}$ & $2272 \pm 1100 \mathrm{~d}(5)$ & $(2$ or fewer $)$ & $5883 \pm 3148 \mathrm{~d}(6)$ & $(2$ or fewer $)$ \\
\hline
\end{tabular}

15-16 normal-looking roots were sampled at random from 23-24 roots per grown per beaker or growth tube. Ten roots with $\mathrm{VC}$ were selected at random from among those for image analysis, unless there were fewer than ten with VC, indicated by (n). $\mathrm{n}<3$ was considered too few to provide a reliable value. Shown are means $\pm \mathrm{SD}$; units are square micrometers. Pairs indicated by $a, b, c, d$ were significantly different from each other $(\mathrm{p} \leq 0.10)$. 
relatively small. In contrast, in hypoxic conditions, such as during flooding or exposure to low-oxygen gas, cavity formation frequency was much greater (Fig. 7) and the size of cavities was usually larger in comparison to those few that formed in the controls (Table 1).

Although the present study did produce some data that suggest that water saturation is a separate factor from hypoxia in the induction of vascular cavities, these results were somewhat equivocal. Low-oxygen air alone caused more frequent cavity formation in the more mature primary tissues than hypoxia caused by flooding (Fig. 7). Since one would predict the reverse to be the case if there were to be differences at all, this surprising result begs further inquiry. The root tip plays an essential role in root growth and requires more oxygen than other tissues of a root (Drew et al. 1994). In the present study the frequency of VC was greater near the tip when roots were suddenly flooded or exposed to low-oxygen gas, and when they occurred in older $5 \mathrm{~d}$ controls they were more common farther back (Fig. 7). We speculate that in $5 \mathrm{~d}$ controls cavities may have formed near the tip as with chronic $\mathrm{VC}$ at an earlier root developmental stage, perhaps beginning around $4 \mathrm{~d}$ (Fig. 7), but they did not always continue to develop over time, as previously reported (Lu et al., 1991).

In other respects the growth tube gas system produced results nearly identical to flooding intact root systems. We look forward to using this experimental system to further explore these questions and to evaluate other species that are known to respond to hypoxia somewhat differently than pea, e.g. maize and rice.

\section{Acknowledgments}

We gratefully acknowledge Sachiko Ishii for technical assistance, data management, and figure preparation and Kunihiko Sakurada for his technical support at Takushoku University. We are also indebted to Dr. Thomas L. Rost (University of California, Davis CA, USA) and Dr. Nancy Smith-Huerta (Miami University, Oxford OH, USA) for critically evaluating early versions of the manuscript, and anonymous reviewers for useful comments on later versions. We thank Dr. Tadashi Hirasawa (Tokyo University of Agriculture and Technology, Tokyo, Japan) for information about water potential in vermiculite.

\section{References}

Armstrong W 1970 Rhizosphere oxidation in rice and other species: a mathematical model based on the oxygen flux component. Physiol. Plant. 23: 623-630.
Atwell BJ, Drew MC, Jackson MB 1988 The influence of oxygen deficiency on ethylene synthesis, 1-aminocyclopropane-1-carboxylic acid levels and aerenchyma formation in roots of Zea mays. Physiol. Plant. 72: $15-22$

Drew MC 1977 Oxygen deficiency and root metabolism: injury and acclimation under hypoxia and anoxia. Ann. Rev. Plant Physiol. Plant Mol. Biol. 48: 224-250.

Drew MC, Jackson MB, Giffard S 1979 Ethylene-promoted adventitious rooting and development of cortical air spaces (aerenchyma) in roots may be adaptive responses to flooding in Zea mays L. Planta 147: 83-88.

Drew MC, Saglio PH, Pradet A 1985 Larger adenylate energy charge and ATP/ADP ratios in aerenchymatous roots of Zea mays in anaerobic media as a consequence of improved internal oxygen transport. Planta 165: 51-58.

Drew MC, Cobb BG, Johnson JR, Andrews D, Morgan PW, Jordan W, He CJ 1994 Metabolic acclimation of root tips to oxygen deficiency. Ann. Bot. 74: 281-286.

Drew MC, He CJ, Morgan PW 2000 Programmed cell death and aerenchyma formation in roots. Trends Plant Sci. 5: 123-127.

Evans DE 2003 Aerenchyma formation. New Phytol. 161: 35-49.

Gladish DK, Niki T 2000 Factors inducing cavity formation in the vascular cylinders of pea roots (Pisum sativum L., cv. Alaska). Environ. Exp. Bot. 43: 1-9.

Gladish DK, Xu,J, Niki T 2006 Apoptosis-like programmed cell death occurs in procambium and ground meristem of pea (Pisum sativum L.) root tips exposed to sudden flooding. Ann. Bot. 97: 895-902.

Gladish DK, Niki T 2008 Ethylene is involved in vascular cavity formation in pea (Pisum sativum) primary roots. Plant Root 2: 38-45.

Gunawardena AHLAN, Pearce DM, Jackson MB, Hawes CR, Evans DE 2001 Characterisation of programmed cell death during aerenchyma formation by ethylene or hypoxia in roots of maize (Zea mays L.). Planta 212: 205-214.

Justin SHFW, Armstrong W 1987 The anatomical characteristics of roots and plant response to soil flooding. New Phytol. 106: 465-495.

Kalita PK 1999 Transient finite element method solution of oxygen diffusion in soil. Ecol. Model. 118: 227-236.

Lu P, Gladish D, Rost TL 1991 Temperature-induced cavities and specialized parenchyma cells in the vascular cylinder of pea roots. Amer. J. Bot. 78: 729-739.

Niki T, Gladish DK, Lu P, Rost TL 1995 Cellular changes precede cavity formation in the vascular cylinders of pea roots (Pisum sativum L., cv. "Alaska"). Int. J. Plant Sci. 156: 290-302.

Niki T, Gladish DK 2001 Changes in growth and structure of pea primary roots (Pisum sativum L. cv. Alaska) as a result of sudden flooding. Plant Cell Physiol. 42: 697-702.

Ober ES, Sharp RE 1996 A microsensor for direct measurement of $\mathrm{O}_{2}$ partial pressure within plant tissues. J. Exp. Bot. 47: 447-454.

Ponnamperuma FN 1984 Effects of flooding on soils. In: Kozlowski EE, Ed., Flooding and Plant Growth. Academic Press, Orlando FL, pp. 9-45.

Rost TL, Lu P, Gladish DK 1991 The occurrence of vascular cavities and specialized parenchyma cells in the roots of cool-season legumes. Bot. Acta 104: 300-305. 


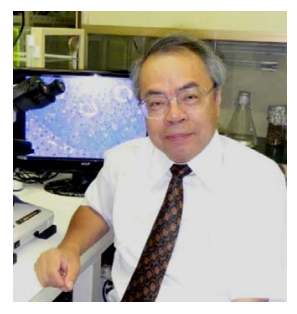

Dr. Teruo Niki is interested in

morphological and physiological

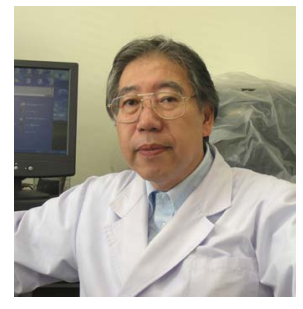

Dr. Mitsuo Takahashi is an oxygen chemist interested in morphological and physiological changes in plant low oxygen conditions.

roots resulting from hypoxia.

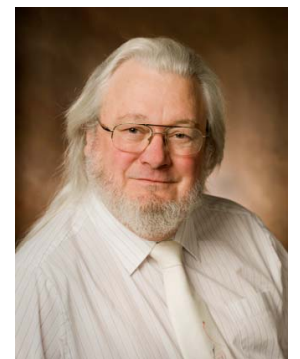

Dr. Daniel K. Gladish has studied the effects of temperature and hypoxia on root development, and he is currently studying the role of programmed cell death in root development. 